\title{
Characterizing differences in precipitation regimes of extreme wet and dry years: implications for climate change experiments
}

\author{
ALAN K. KNAPP ${ }^{1}$, DAVID L. HOOVER ${ }^{1}$, KEVIN R. WILCOX $^{1}$, MEGHAN L. AVOLIO $^{2}$, \\ SALLYE. KOERNER ${ }^{1}$, KIMBERLY J. LA PIERRE ${ }^{3}$, MICHAEL E. LOIK $^{4}$, YIQI LUO ${ }^{5}$, \\ OSVALDO E. SALA ${ }^{6}$ and MELINDA D. SMITH ${ }^{1}$ \\ ${ }^{1}$ Department of Biology, Graduate Degree Program in Ecology, Colorado State University, Fort Collins, CO 80523, USA, \\ ${ }^{2}$ Department of Biology, University of Utah, Salt Lake City, UT 84112, USA, ${ }^{3}$ Department of Integrative Biology, University of \\ California, Berkeley, CA 94720, USA, ${ }^{4}$ Department of Environmental Studies, University of California, Santa Cruz, CA 95064, \\ USA, ${ }^{5}$ Department of Microbiology and Plant Biology, University of Oklahoma, Norman, OK 73019, USA, ${ }^{6}$ School of Life \\ Sciences, Arizona State University, Tempe, AZ 85287, USA
}

\begin{abstract}
Climate change is intensifying the hydrologic cycle and is expected to increase the frequency of extreme wet and dry years. Beyond precipitation amount, extreme wet and dry years may differ in other ways, such as the number of precipitation events, event size, and the time between events. We assessed 1614 long-term (100 year) precipitation records from around the world to identify key attributes of precipitation regimes, besides amount, that distinguish statistically extreme wet from extreme dry years. In general, in regions where mean annual precipitation (MAP) exceeded $1000 \mathrm{~mm}$, precipitation amounts in extreme wet and dry years differed from average years by $\sim 40 \%$ and $30 \%$, respectively. The magnitude of these deviations increased to $>60 \%$ for dry years and to $>150 \%$ for wet years in arid regions (MAP $<500 \mathrm{~mm}$ ). Extreme wet years were primarily distinguished from average and extreme dry years by the presence of multiple extreme (large) daily precipitation events (events $>99$ th percentile of all events); these occurred twice as often in extreme wet years compared to average years. In contrast, these large precipitation events were rare in extreme dry years. Less important for distinguishing extreme wet from dry years were mean event size and frequency, or the number of dry days between events. However, extreme dry years were distinguished from average years by an increase in the number of dry days between events. These precipitation regime attributes consistently differed between extreme wet and dry years across 12 major terrestrial ecoregions from around the world, from deserts to the tropics. Thus, we recommend that climate change experiments and model simulations incorporate these differences in key precipitation regime attributes, as well as amount into treatments. This will allow experiments to more realistically simulate extreme precipitation years and more accurately assess the ecological consequences.
\end{abstract}

Keywords: climate change experiments, climate extremes, drought, ecoregions, global patterns, precipitation, rainfall patterns

Received 22 October 2014; revised version received 24 January 2015 and accepted 27 January 2015

\section{Introduction}

An increase in the frequency and magnitude of climate extremes is one of the most consistent changes forecast by global climate models (Smith, 2011a; IPCC, 2013; Singh et al., 2013; Fischer et al., 2013). Indeed, observed precipitation trends worldwide already support predictions of increased precipitation extremes - part of an ongoing intensification of the global hydrological cycle (Trenberth et al., 2003; Huntington, 2006; Durack et al.,

Correspondence: Alan K. Knapp, Department of Biology, Graduate Degree Program in Ecology, Colorado State University, Ft. Collins, CO 80526, USA, tel. 970491 7010, fax 970491 0649, e-mail: aknapp@colostate.edu
2012; Marvel \& Bonfils, 2013). These extremes are now evident from reports of record high-rainfall years, extensive and extended periods of meteorological drought, and shifts in intra-annual rainfall patterns. The latter are characterized by increased heavy rainfall events from high energy convective systems, fewer events overall (thus more dry days), and longer intervening dry periods between events (Karl \& Knight, 1998; Groisman et al., 1999, Groisman et al., 2005; Easterling et al., 2000a,b; Karl \& Trenberth, 2003; Huntington, 2006; Min et al., 2011; Janssen et al., 2014).

Here, we focus on extreme precipitation years, which are predicted to increase in frequency and intensity on interannual timescales (Trenberth et al., 2003; IPCC, 2013; Fischer et al., 2013) with both ecological and 
evolutionary impacts (Pratt \& Mooney, 2013). Although extreme wet and dry years for any given locale will obviously differ in total precipitation amount, it is less clear how other attributes of precipitation regimes may differ. For example, event size and the proportion of precipitation that falls in different event size classes have been reported to differ substantially between extreme wet and dry years in both Northern and Southern Hemispheres (Sala et al., 1992; Golluscio et al., 1998; Dettinger et al., 2011; Bolinger et al., 2014). In contrast, the average number of dry days between periods of precipitation in Israel did not vary despite an almost 10 -fold range in mean annual precipitation (MAP, Aviad et al., 2009) suggesting that this attribute may be less sensitive to precipitation amount. Because there is now abundant evidence that event size (Knapp et al., 2002, 2008; Heisler-White et al., 2009; Raz-Yaseef et al., 2010; Cherwin \& Knapp, 2012; Avolio \& Smith, 2013; Kulmatiski \& Beard, 2013; Coe \& Sparks, 2014), event number (Porporato et al., 2004; Travers \& Eldridge, 2013; Zhang et al., 2013; Peng et al., 2013; Goldstein \& Suding, 2014), and the timing of precipitation events (Zeglin et al., 2013; Zeppel et al., 2014) each may influence ecological responses independent of total precipitation amount, an assessment of how extreme precipitation years differ in precipitation attributes beyond amount is needed. Without such an assessment, our ability to forecast ecosystem responses to extremes in precipitation may be compromised; particularly if only precipitation amount is considered in experiments and model simulations while neglecting other important attributes of precipitation regimes. Indeed, how these attributes vary between wet and dry years across multiple ecosystem types (e.g., deserts, grasslands, and forests) would be especially valuable for distributed multisite experiments designed to assess the ecological impacts of extremes in precipitation.

Our goal was to characterize how extreme wet and dry years differ from each other and from average years and to determine whether these differences vary with mean annual precipitation or across major terrestrial ecoregions of the globe. Our approach focused on precipitation inputs as these are most often manipulated in field experiments as well as model simulations, and globally distributed records of precipitation inputs are plentiful. We recognize that the ecological impacts of changes in precipitation inputs can be modified by many hydrological properties specific to particular ecosystems (e.g., potential evapotranspiration and the timing of precipitation inputs, soil infiltration rates, runoff and soil water storage capacity, plant rooting depth, Knapp et al., 2008; Leuzinger \& Körner, 2010; Hovenden et al., 2014). However, this 'input' perspective is consistent with that of the IPCC (2012) which, for example, defines drought as a 'prolonged absence or marked deficiency of precipitation' inputs with the recognition that this meteorological definition may lead to a variety of responses depending on ecosystem hydrology (Yu \& D'Odorico, 2014). We used long-term (100 year) precipitation records from 1614 sites that spanned a broad precipitation gradient $(\sim 115-2595 \mathrm{~mm}$ MAP), defining extreme years statistically based on these historical records of precipitation for each site. First, for all sites, we determined how much precipitation amount increased or decreased in extreme precipitation years relative to average years. Second, we focused on five key precipitation regime attributes known to influence ecological processes (daily precipitation event size, event frequency, dry days between events, and the frequency of extreme daily events and extreme dry periods) and determined how these differed between climatically extreme years, and how these varied among 12 major terrestrial ecoregions. Finally, we use these results to formulate recommendations for the design of precipitation manipulation experiments that focus on extreme precipitation years.

\section{Materials and methods}

\section{Data and selection criteria}

Site-based daily precipitation records were obtained from the Global Historical Climatology Network (GHCN; http:// www.ncdc.noaa.gov/oa/climate/ghcn-daily/). Only records from sites that met the following criteria were used: (i) records spanned a common 100-year period (1901-2000); (ii) missing values in daily precipitation records comprised $<10 \%$ of the total number of days; (iii) the probability distribution of total annual precipitation fit either normal or lognormal distributions, based on a Shapiro-Wilks test; and (iv) the minimum daily resolution for detecting a precipitation event was $\leq 0.3 \mathrm{~mm}$. Based on these criteria, data sets from 1614 sites were obtained and each was assigned to one of Bailey's ecoregions based on site latitude and longitude (Bailey, 1983, 1989; http:/ / www.fs.fed.us/land/ecosysmgmt/index.html). For those sites in which the minimum daily precipitation resolution was $<0.3 \mathrm{~mm}$, we replaced all daily precipitation values $<0.3 \mathrm{~mm}$ with zero to maintain equal precision and consistency across sites when calculating event number, time between events, etc.

\section{Precipitation attributes}

Extremes in annual precipitation amount and precipitation regime attributes were defined statistically (Jentsch, 2006) based on the 100-year records at each site. Statistical thresholds for defining climate extremes, focusing on the tails of the distribution from a reference time period, vary depending on the meteorological parameter, but thresholds generally range among the 10th (Easterling et al., 2000a,b), 5th (Smith, 2011a), 
and 1st percentile (Jentsch et al., 2007). Because our goal was to broadly characterize the attributes of extreme precipitation years, we varied thresholds for defining extremity among the metrics assessed to ensure that there were adequate numbers of values to analyze. Thus, based on the historical probability distribution of total annual precipitation at each site, extreme wet years were defined as those with total annual precipitation $>90$ th percentile of the historical distribution, and dry years were defined as those with total annual precipitation $<10$ th percentile. These thresholds resulted in average standardized precipitation indices (SPI) across all sites of +1.85 and -1.82 , respectively, which corresponded to years classified as 'very wet' to 'extremely wet' and 'severely dry' to 'extremely dry' (McKee et al., 1993). For comparative analyses, average years were defined as those where total annual precipitation was between the 45 th and 55 th percentile (SPI $=0$ ). By selecting the 10th percentile tails, we identified an average of 9.6 extreme wet and 8.1 extreme dry years per site.

For each of the 1614 data sets, mean precipitation amount was determined for those years classified as extremely wet or dry $\left(\mathrm{MAP}_{\text {Extreme }}\right)$, and the relative $(\%)$ deviation in $\mathrm{MAP}_{\text {Extreme }}$ from MAP (100-year average) was calculated as the difference between MAP $_{\text {Extreme }}$ and MAP divided by MAP and multiplied by 100. A nonlinear regression model was used to describe how this relative deviation in extreme precipitation amount varied with MAP (PROC nlin, SAS v. 9.3, Cary, NC, USA).

In a subset of the 1614 data sets, we assessed how precipitation attributes of extreme wet and dry years differed across a broad range of ecosystem types identified at the level of Bailey's terrestrial ecoregion divisions (Bailey, 1983, 1989). Although Bailey recognized 14 ecoregion divisions, we were unable to evaluate tundra and rainforest divisions due to lack of adequate replicates of 100-year climate records. Thus, these ecoregions were excluded, as well as sites located in Bailey's 'mountain' provinces due to the high degree of spatial variability associated with orographic effects on precipitation regimes. From the remaining sites in each of the 12 ecoregions, 12 data sets were randomly selected $(n=144$ total) for the analyses of precipitation attributes.

For each extreme wet, average, and extreme dry year in the 144 data sets, we calculated the following attributes: (i) the number of precipitation events (\# Events) = the number of days with precipitation $\geq 0.3 \mathrm{~mm}$; (ii) mean event size (Event Size $)=$ mean daily precipitation amount for days with precipitation events; (iii) consecutive dry days $(C D D)=$ the average number of days in the dry period between precipitation events; (iv) extreme daily precipitation events (\# Extreme Events) = number of events per year when the daily precipitation amount exceeded the 99th percentile of daily precipitation amounts for the entire 100-year record; and (v) extreme consecutive dry days (\# Extreme CDD) $=$ number of dry periods that exceeded in length (days) the 95th percentile of all dry periods in the 100-year record. These attributes were selected to capture key characteristics of extreme precipitation years, based on previous assessments of changing precipitation regimes and recent analyses of trends in climate extremes (Frich et al., 2002; IPCC, 2013).

\section{Ordination analyses}

Each of the precipitation regime attributes described above was normalized for each site using the equation:

$$
X_{n}=\frac{\left(X_{i, s}-\mu_{s}\right)}{s d_{s}}
$$

where $X_{n}$ is the normalized value, $X_{i, s}$ is the individual value for year $i$ within data set $s, \mu_{s}$ is the mean value for data set $s$, and $s d_{s}$ is the standard deviation of data set $s$. We normalized to allow for the comparison of attributes with different units and thus different magnitudes of variance in the dissimilarity matrices.

The normalized data for all five attributes quantified for each of the 144 data sets were incorporated into a principle components analysis (PCA) for visualization, and a permutational multivariate analysis of variance (perMANOvA) was used to determine whether extreme wet, extreme dry, and average years differed when these five attributes were considered collectively. If 'year type' (extreme wet, average or extreme dry) significantly differed with regard to precipitation regime attributes based on the perMANOVA test, we then determined the relative contribution that each precipitation regime attribute made to divergence among extreme wet, extreme dry, and average years using a Euclidean distance-based similarity percentage (SIMPER) analysis. These analyses were performed for all 144 data sets combined as well as separately for each of the 12 ecoregions. Finally, mean values for each of the five precipitation regime attributes were compared among extreme wet, extreme dry, and average years for all ecoregions combined, as well as for individual ecoregions, using a mixedmodel ANOVA, with year type as a fixed factor and individual sites (144 for all ecoregions and 12 within an ecoregion) as a random variable. PCA, PERMANOVA, and SIMPER analyses were performed using PRIMER (v. 6.1.3, Ivybridge, UK), and the ANOVA was performed in SAS (v. 9.3).

\section{Results}

Based on the 90th and 10th percentile thresholds for defining extreme wet and dry years, respectively, there was a clear pattern of asymmetry between these types of years with regard to their relative deviation in precipitation amount from average years (Fig. 1). In general, for sites with MAP above $1000 \mathrm{~mm}$, annual precipitation in extreme wet years was $\sim 40 \%$ greater than in average years, and this increased dramatically as MAP decreased in more arid sites (up to $>150 \%$ at $100 \mathrm{~mm}$ $\mathrm{MAP})$. In contrast, annual precipitation in extreme dry years was $\sim 30 \%$ below average for sites with MAP $>1000 \mathrm{~mm}$, and this deviation increased to $>60 \%$ as MAP decreased to $100 \mathrm{~mm}$ (Fig. 1). This pattern of greater relative deviations from average occurring when MAP is low could result if absolute deviations from average were constant for wet and dry years (due to a decreasing denominator). But, this was not the case as the absolute deviation in precipitation from average for extreme wet and dry years decreased with MAP. The 


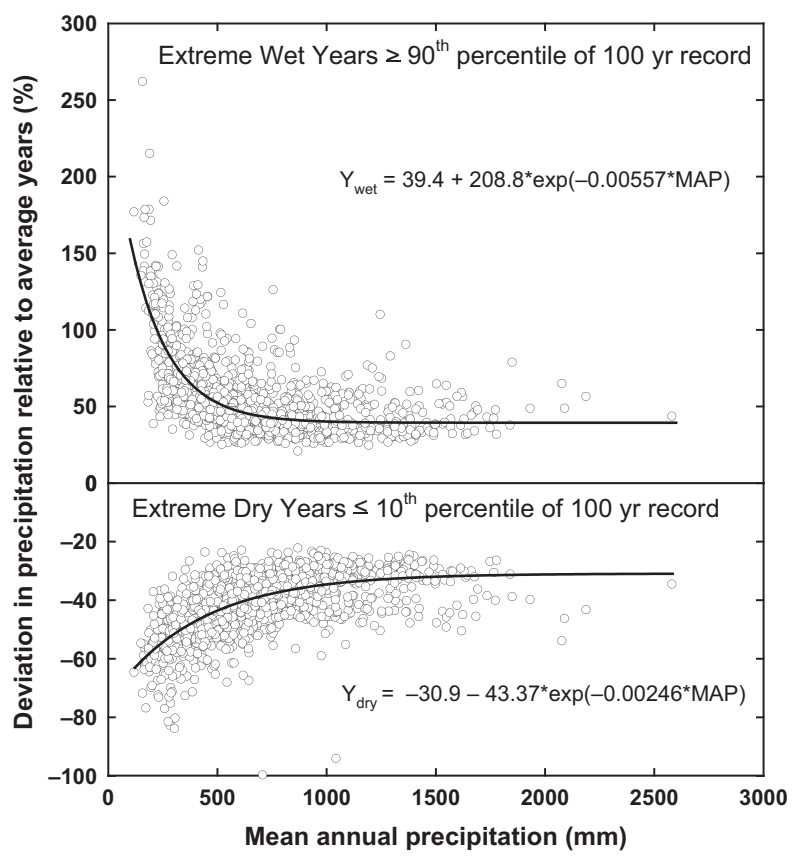

Fig. 1 Relative (\%) deviation in precipitation amount for extreme wet and extreme dry years compared to the mean of average years across 1614 sites worldwide. Average years were defined as those between the 45th and 55th percentiles of the historical (100 year) distribution of annual precipitation amounts; extreme wet years were $>$ the 90th percentile, and extreme dry years were $<$ the 10th percentile. Lines represent best fit nonlinear regression and both are highly significant $(P<0.01)$.

decrease in absolute deviation of precipitation from average at low MAP was not sufficient, however, to maintain the relative deviation for extreme years constant, and this explains the overall pattern observed.

Given the 100-year duration of these precipitation records and reports of local and regional-scale temporal trends in precipitation extremes and amount (e.g., Trenberth et al., 2003; Greve et al., 2014), we assessed the 144 data sets for temporal patterns at the site as well as the ecoregion scale. Consistent with previous reports, the majority of sites showed no statistically significant temporal pattern of increasing or decreasing annual precipitation amount over the 100-year period (Table S3); however, when there were significant relationships, precipitation tended to increase over time. Because of the low number of extreme years at each site, we assessed temporal trends in the occurrence of extreme wet and dry years on a decadal timescale. As expected, we found that statistically defined extreme wet years have occurred more frequently in more recent decades relative to earlier decades, with this pattern evident in five of the 12 ecoregions as well as overall (Fig. S2). No such decadal patterns were evident in the occurrence of extreme dry years, however.
Collectively, the five precipitation regime attributes of extreme wet, extreme dry, and average years clearly differed when all 144 sites were combined (perMANOVA Pseudo-F $=422.06, P<0.01)$ with the first two axes of the principle components analysis (PCA) explaining $>85 \%$ of the variance among extreme wet, average, and extreme dry year types (Fig. 2). Furthermore, when each ecoregion was analyzed separately, differences among years in these precipitation regime attributes also were significant (Table S1). When comparing extreme wet vs. extreme dry years, the attribute that was most important for distinguishing these two types of years was the \# Extreme Events, followed by Event Size and \# Events (Fig. 3). However, all five attributes differed significantly between extreme wet and dry years when assessed independently (Table 1), even the \# Extreme CDD, which contributed the least to divergence between extreme wet and dry years. Remarkably, similar results were found for each individual ecoregion (Fig. 4, Table S1) with the \# Extreme Events contributing most to divergence between wet and dry years in 11 of the 12 ecoregions. Event Size and \# Events alternated equally among ecoregions as the second most important attribute for distinguishing extreme years, with \# Extreme CDD being the least important in all ecoregions. Nonetheless, for each ecoregion, all five attributes differed significantly between extreme wet and dry years (Table S2).

The \# Extreme Events also was the most important precipitation regime attribute distinguishing extreme wet from average years, with all other attributes differing significantly and contributing to differences in wet vs. average years in the same order of importance as they did when comparing wet vs. dry years (Fig. 5, Table 1). However, the pattern differed when comparing extreme dry and average years (Fig. 5). For most sites, the number of extreme events was relatively low in average years, and these were less common in extreme dry years; thus, this attribute had less resolving power for distinguishing these two types of years. Rather, the length of time between events (CDD) was more important for distinguishing extreme dry from average years (Fig. 5 bottom). These patterns also were remarkably consistent when the 12 ecoregions were analyzed separately, although in some ecoregions CDD and Extreme CDD did not differ significantly between wet and average years (Fig. S1).

\section{Discussion}

\section{Attributes of extreme dry and wet years}

The importance of climate extremes from an ecological and socioeconomic perspective is widely recognized 


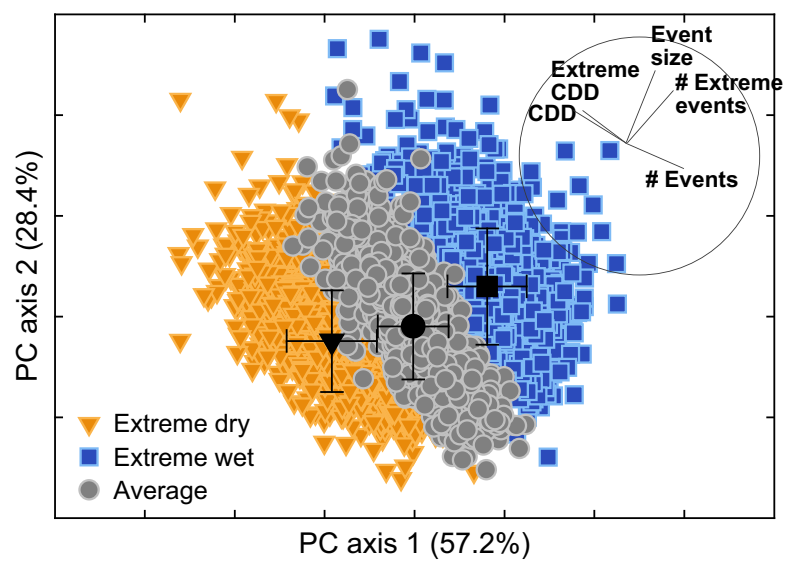

Fig. 2 Principle components analysis of five precipitation regime attributes in extreme dry (annual precipitation in the 10th percentile), extreme wet (annual precipitation in the 90th percentile), or average (between 45 th and 55 th percentiles) years for 144 sites representing 12 terrestrial ecoregions ( $n=12$ sites/ ecoregion). Precipitation regime attributes: the number of extreme (99th percentile) rainfall events (\# Extreme Events), average event size (Event Size), the number of rainfall events (Event \#), number of extreme (99th percentile) dry periods [Extreme consecutive dry days (CDD)], and average length of dry period (CDD). Small symbols represent individual years within a station while large symbols indicate means of dry, wet, or normal years. Error bars represent 1 standard deviation from the mean. Vectors in the upper right show the direction of contribution by the five precipitation regime attributes. Axis 1 explained $57.2 \%$ of the variance and was positively related to Event \# and negatively to CDD (highest eigenvector scores); axis 2 explained $28.4 \%$ of the variance and was positively related to Event Size and \# Extreme Events.

(Smith, 2011a). Driven by forecasts of an increase in the frequency and intensity of extremes in precipitation (e.g., IPCC, 2013), our goal was to identify the key attributes of precipitation regimes, beyond amount, that characterize extreme wet and dry years. Furthermore,

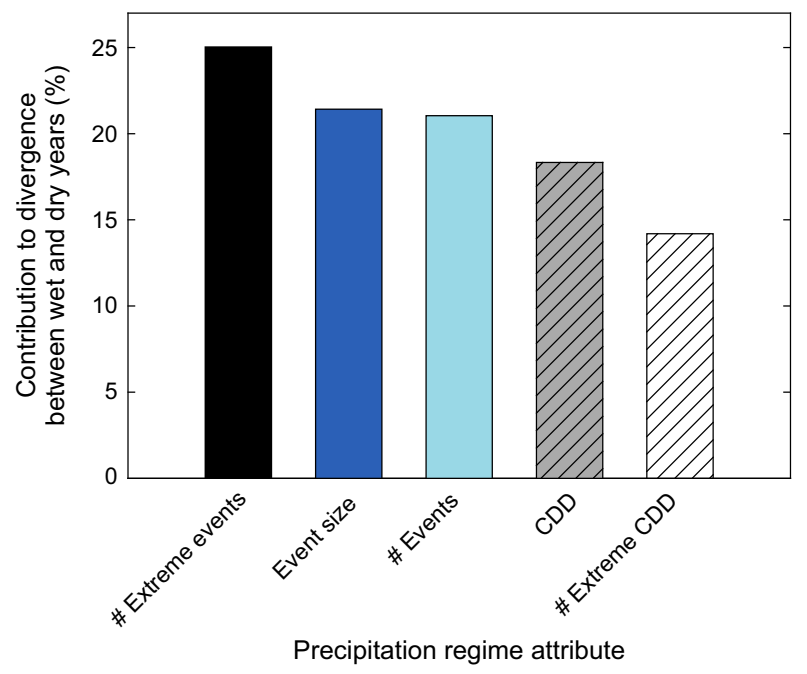

Fig. 3 The percentage contribution to divergence between extreme wet and dry years for each of five precipitation regime attributes based on SIMPER analysis. Bars are the average percentage contribution across all sites $(n=144)$ Precipitation regime attributes: number of extreme (99th percentile) rainfall events (\# Extreme Events), average event size (Event Size), the number of rainfall events (Event \#), number of extreme (99th percentile) dry periods [\# Extreme consecutive dry days (CDD)], and average length of dry period (CDD). Data were normalized independently for each station before performing SIMPER analysis. All attributes differed significantly between extreme wet and dry years based on individual ANOvas of each attribute (see Table 1).

we assessed how these attributes varied among major global terrestrial ecoregions that span an extensive range of MAP. We used a synoptic approach to analyze 1614 long-term (100 year) climate records, focusing on those years that met a statistical definition of an extreme wet ( $>90$ percentile of the historic record) or dry $(<10$ percentile) year and contrasting these with

Table 1 Results from one-way ANOVA for each precipitation attribute for the combined 144 site data set representing 12 ecoregions. In each model, site was a random variable and the effect tested was type of year (Wet, Average, Dry, denominator DF $=2$, numerator $\mathrm{DF}=3767)$

\begin{tabular}{|c|c|c|c|c|c|c|}
\hline \multirow[b]{2}{*}{ Precipitation attribute } & \multirow[b]{2}{*}{ Units } & \multirow[b]{2}{*}{$F$-value } & \multirow[b]{2}{*}{$P$-value } & \multicolumn{3}{|l|}{ Mean (SE) } \\
\hline & & & & Wet & Average & Dry \\
\hline \# Extreme Events & \# of events & 2005.1 & $<0.0001$ & $4.5(0.1)$ & $2.1(0.1)$ & $0.8(0.1)$ \\
\hline Event \# & \# of events & 1717.7 & $<0.0001$ & $106.7(3.5)$ & 90.9 (3.5) & $72.1(3.5)$ \\
\hline Event Size & $\mathrm{mm}$ & 1029.6 & $<0.0001$ & $10.7(0.3)$ & $8.2(0.3)$ & $6.3(0.3)$ \\
\hline Extreme CDD & \# of periods & 434.6 & $<0.0001$ & $1.9(0.1)$ & $2.5(0.1)$ & $3.5(0.1)$ \\
\hline CDD & days & 340.2 & $<0.0001$ & $6.3(0.5)$ & $7.5(0.5)$ & $10.2(0.5)$ \\
\hline
\end{tabular}

Results are ordered by $F$-value, and mean values for each attribute with standard errors (SE) are also presented. Precipitation regime attributes: the number of extreme (99th percentile) rainfall events (\# Extreme Events), average event size (Event Size), the number of rainfall events (Event \#), number of extreme (99th percentile) dry periods (Extreme CDD), and average length of dry per$\operatorname{iod}(\mathrm{CDD})$. 


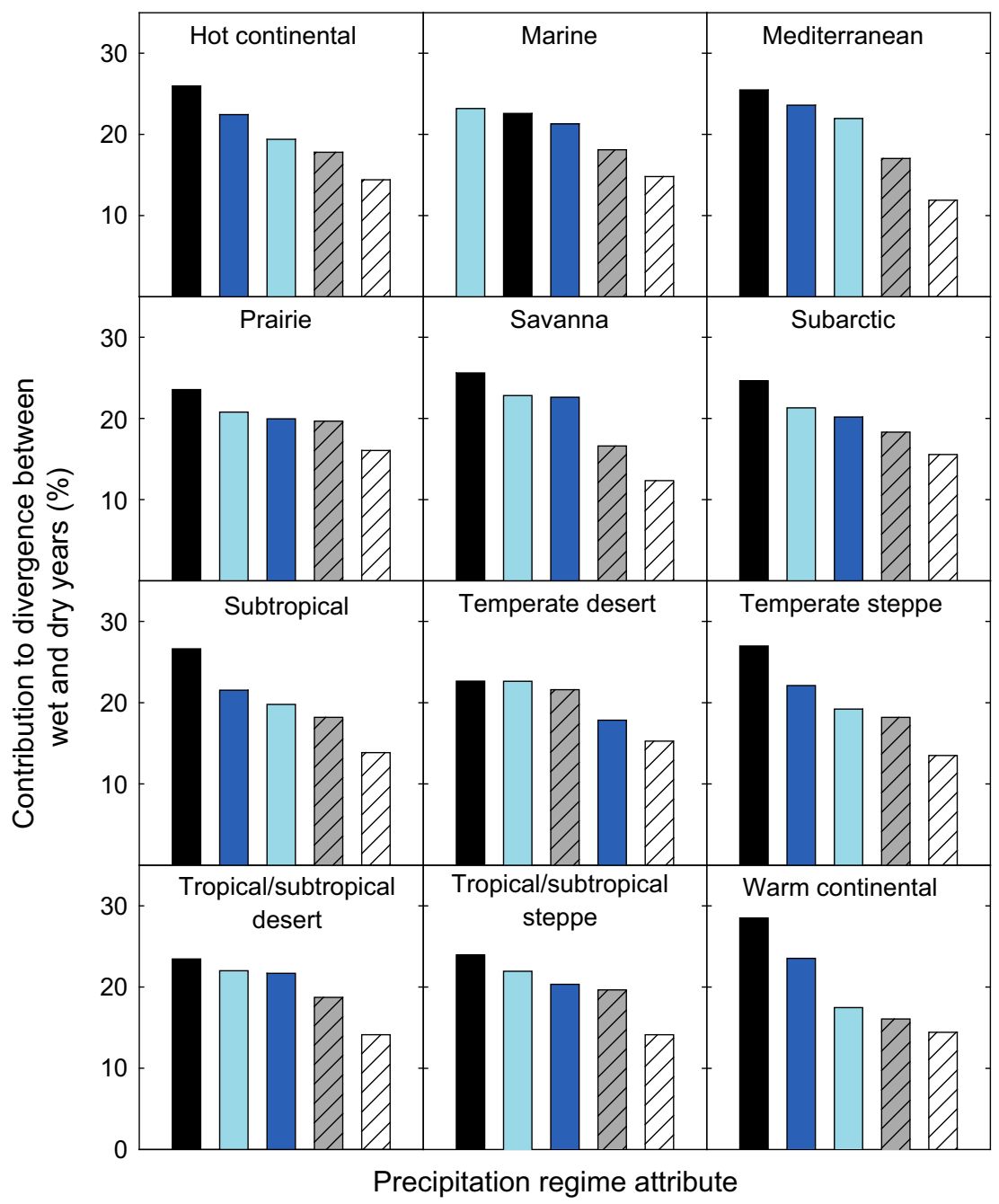

Fig. 4 Percentage contribution of five precipitation regime attributes to divergence between extreme wet and dry years for 12 major terrestrial ecoregions ( $n=12$ sites per ecoregion) based on SIMPER analysis. Precipitation regime attributes: number of extreme (99th percentile) rainfall events (\# Extreme Events), average event size (Event Size), the number of rainfall events (Event \#), number of extreme (99th percentile) dry periods [\# Extreme consecutive dry days (CDD)], and average length of dry period (CDD). Bars designate precipitation attributes as in Fig. 3. Data were normalized independently for each station before performing the SIMPER analysis. All precipitation regime attributes differed significantly between wet and dry years (ANOVA, $P<0.01$ ).

each other and average (45-55 percentile) precipitation years.

The emergent pattern from our analysis was that at MAP $>1000 \mathrm{~mm}$, the relative deviation in precipitation amount from average that is necessary to meet a statistical definition of extremity was relatively constant at this global scale. But at MAP $<500 \mathrm{~mm}$ and particularly in arid regions, greater proportional deviations from average years were required to achieve statistical extremity (Fig. 1). This pattern is not a product of a constant absolute deviation in precipitation and a decreasing denominator at low MAP. Indeed, absolute differences in precipitation between extreme and average years varied considerably across the MAP gradient.
But, this pattern is consistent with the well-known inverse relationship between precipitation amount and interannual variability (Knapp \& Smith, 2001; Davidowitz, 2002). High interannual variability in precipitation has long been recognized as a key driver of the structure and function of arid ecosystems (Noy-Meir, 1973). Thus, for a given year to be classified statistically as extremely wet or dry in more arid ecosystems, larger deviations in precipitation (relative to average) would be expected. In contrast, interannual variability in precipitation is generally much lower in mesic ecosystems, and thus, smaller relative deviations in precipitation would meet the criteria for statistical extremity. A second pattern to emerge is that the relative deviation in 


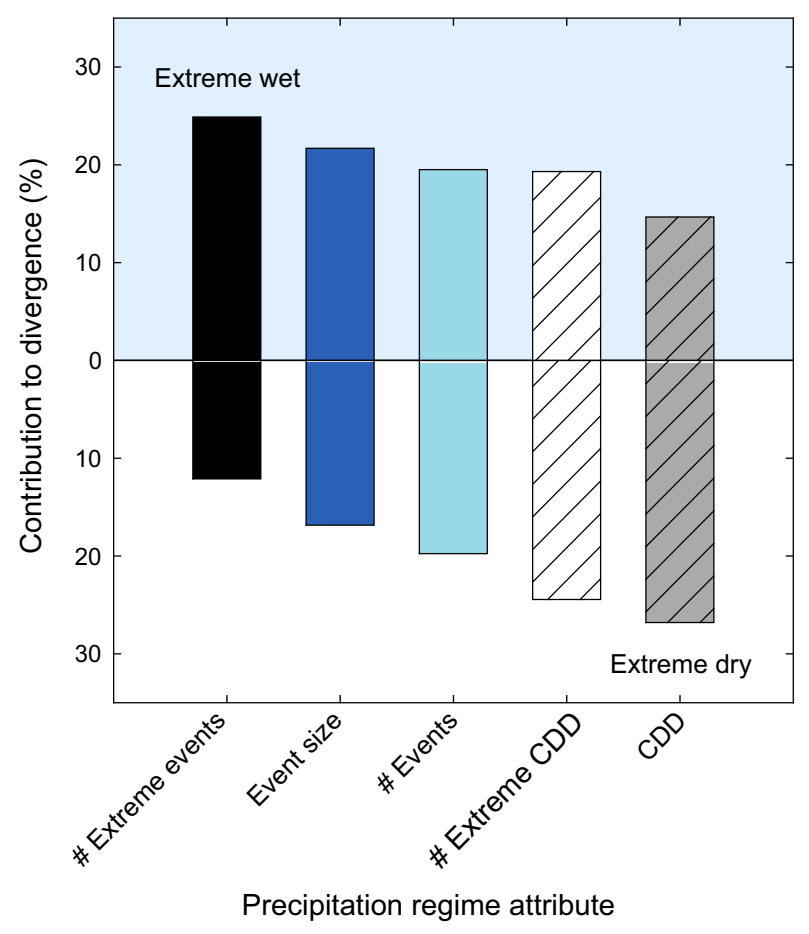

Fig. 5 Percentage contribution of five precipitation regime metrics to divergence between extreme wet and average years (top panel) and extreme dry and average years (bottom panel) across all sites $(n=144)$ based on SIMPER analysis. Precipitation regime attributes: number of extreme (99th percentile) precipitation events (\# Extreme Events), average event size (Event Size), the number of rainfall events (Event \#), number of extreme (99th percentile) dry periods [\# Extreme consecutive dry days (CDD)], and average length of dry period (CDD). Data were normalized independently for each station before performing SIMPER analysis. All precipitation regime attributes differed significantly between wet, average, and dry years (Table 1).

precipitation amount from average years for extreme wet years is larger than for extreme dry years (note the asymmetry in Fig. 1). In particular, in arid regions, this asymmetry occurs in part because reductions in precipitation in dry years are constrained to $100 \%$ (annual precipitation can only be reduced to zero). However, asymmetry between wet and dry years persisted even above $1000 \mathrm{~mm}$ MAP suggesting that this uneven pattern (extreme wet years being $40 \%$ wetter than average with extreme dry years $30 \%$ drier than average) requires further exploration, particularly with regard to the ecological consequences.

The five attributes of precipitation regimes that we used to characterize extreme wet and dry years, all differed significantly between extreme years (Table 1). Moreover, when combined in a multivariate analysis, they clearly distinguished extreme years from each other and from average years (Fig. 2). Although it is not surprising that event size differed between years that are extremely wet vs. dry (Sala et al., 1992), the consistent ranking of these five attributes in explaining divergence between extreme years across all ecoregions was unexpected and is noteworthy (Figs 3 and 4). In particular, the primary importance of extreme daily precipitation events for distinguishing wet from dry and average years across all sites was surprising as was the consistency among quite disparate ecoregions (Figs 4, 5, and S1). Thus it appears that globally, extreme wet years are consistently characterized not only by a large amount of precipitation, but also by the presence of a relatively small number of very large daily precipitation events (exceeding the 99th percentile of all events = \# Extreme Events) and not simply by more individual events. It is important to note that because the vast majority of individual daily events in most ecoregions are very small, such statistically extreme precipitation events need not be exceptionally large - for example, daily events that exceed the 99th percentile in the deserts of central New Mexico (USA) were $\sim 23 \mathrm{~mm}$, compared to $\sim 44 \mathrm{~mm}$ in humid grasslands in Kansas (USA) and $\sim 41 \mathrm{~mm}$ in deciduous forests in Massachusetts (USA). Thus, when considered independently, such daily events may not lead to substantial runoff or flooding unless intensity $(\mathrm{mm} / \mathrm{min})$ is extremely high as well. Although average event size and event number also increase in extreme wet vs. dry years (Table 1), the primary role of these very large daily events in contributing to extreme precipitation years is striking. For example, if the precipitation input from extreme daily events is subtracted from the annual total for the 144 sites analyzed, precipitation inputs are reduced to only $7 \%$ above average years for extreme wet years. Moreover, if we extend the statistical definition of extreme daily event to those exceeding the 95th percentile (rather than 99th) and remove these, then precipitation amounts for extreme wet years are reduced to $\sim 10 \%$ below average, and average years become extremely dry. Thus, these few large daily events have tremendous importance for determining precipitation totals in all ecoregions and given that extreme wet years are increasing over time (Fig. S2), this suggests that the frequency of these extreme daily events is also increasing (Trenberth et al., 2003).

\section{Ecosystem responses to large precipitation events}

Given forecasts that extreme daily precipitation events will increase in frequency and magnitude in the future, recent research has begun to assess their ecological importance. To date, increases in large precipitation events have been proposed to be particularly important in more arid ecosystems. In arid systems, a shift to fewer, larger events may increase soil water storage at 
greater depths and reduce soil water lost to evaporation where compared to many small events that total to the same precipitation amount (Knapp et al., 2008). Results from limited field experiments support this prediction (Heisler-White et al., 2009; Thomey et al., 2011). There is also intriguing evidence that very large events occurring in dry years may compensate for low annual precipitation amounts. In arid forests in Israel, Raz-Yaseef et al. $(2010,2012)$ reported that forest productivity was influenced more by the occurrence of large storms than total precipitation amount, with some aspects of ecosystem function maintained during years with well-below average precipitation as long as a few large rain events occurred. Similarly, Cherwin \& Knapp (2012) attributed a surprising lack of response to experimental drought imposed in semi-arid grasslands in some years to large events compensating for the overall reduction in precipitation. In these examples, it appears that these large precipitation events did not increase surface runoff at the expense of infiltration and thus did not reduce soil water availability to plant roots and soil organisms (Loik et al., 2004). Finally, Kulmatiski \& Beard (2013) suggest that an increase in large events may favor deep rooted woody plants relative to grasses and accelerate woody plant encroachment in savannas, while $\mathrm{Yu} \&$ D'Odorico (2014) demonstrated that the importance of hydraulic redistribution in ecosystems may increase with precipitation regimes shifted toward fewer but larger events. Thus, failure to consider the role that increasing numbers of large precipitation events may play as climate continues to change may lead to inaccurate forecasts of ecological responses.

Forecast scenarios of increases in the frequency and magnitude of extreme dry years combined with an increase in the proportion of precipitation that occurs as large events suggests that novel climatic conditions (dry years with large daily precipitation events) may mitigate the loss of some ecosystem functions (e.g., aboveground productivity, Cherwin \& Knapp, 2012) if large events can compensate for an overall reduction in rainfall. With respect to ecosystem productivity, 'extreme event compensation' may increase water-use efficiency (WUE) particularly in more arid regions. Recently, Ponce-Campos et al. (2013) assessed aboveground production responses at the biome scale to altered hydroclimatic conditions in the early 21 st century. These altered conditions were characterized by a decadal period of drought, yet they reported surprising ecosystem resilience as evidenced by WUE (ANPP/evapotranspiration) during this period being maintained at levels similar to the late 20th century. Such results are consistent with an increase in the frequency of large events compensating for production losses in dry years and highlight the need to fully explore the consequences of forecast alterations in annual precipitation totals combined with changes in the attributes of precipitation regimes (Klein et al., 2011).

\section{Implications for precipitation manipulation experiments}

Climate change, including hydrological intensification, is expected to impact virtually all biomes globally; however, it is well known that individual ecosystems differ in their sensitivity to changes in climate (Grime et al., 2000; Weltzin et al., 2003; Gerten et al., 2008; Luo et al., 2008; Smith et al., 2009; Vittoz et al., 2009; Smith, 2011a,b; Wu et al., 2013; Moran et al., 2014; Knapp et al., 2015; Wilcox et al., 2015). This has prompted numerous calls for regionally to globally distributed experiments to better understand why some ecosystems are more sensitive to climate change than others (Smith, 2011a,b; Luo et al., 2011; Knapp et al., 2013; Fraser et al., 2012). Given the dramatic ecological responses and socioeconomic consequences that climate extremes may elicit, such coordinated distributed experiments would be particularly valuable for understanding how ecosystems differ in their vulnerability to climate extremes (Smith, 2011a). Ideally, such experiments would be distributed across multiple biomes and would be implemented with identical protocols at all sites (Fraser et al., 2013).

The patterns described by our analysis of precipitation regime attributes have important implications for the design of coordinated distributed experiments, particularly those attempting to simulate extreme wet or dry years (in the field or within modeling frameworks). For example, many treatments designed to increase precipitation amounts do so by adding events during dry periods, adding events at regular intervals, or increasing the number of all event sizes (e.g., Knapp et al., 2001; Gerten et al., 2008; Thomey et al., 2011). However, if these approaches do not increase the number of extreme events, they will not accurately reflect precipitation patterns characteristic of extreme wet years. Equally important for the design of realistic treatments is the reduction in large precipitation events in dry years. It is clear from our analysis that to realistically simulate extreme dry years, extremely large daily events should be reduced or eliminated, and the period of time between events should be increased with the inclusion of some extremely long CDD periods relative to average or wet years (Fig. 5). Both the reduction in total amount of precipitation and increasing CDD can be accomplished by reducing event number, the precipitation attribute that contributed most to the divergence between dry and average years after the CDD attributes (Fig. 5). 
In summary, this global-scale analysis of precipitation regimes for extreme wet and dry years suggests that, beyond precipitation amount, the presence of multiple extreme (large) daily precipitation events during wet years and their relative rarity in extreme dry years are the most important precipitation attributes for distinguishing among extreme wet, average, and extreme dry years. Extreme dry years were further distinguished from average years by an increase in the average length of dry periods between precipitation events. These fundamental differences in precipitation regimes were remarkably consistent when 12 globally important ecoregions were assessed independently - from desert to tropical and marine to subarctic ecoregions. Such consistency facilitates the design of regional and globalscale climate change experiments enabling common and comparable treatments to be imposed in disparate ecosystems.

\section{Acknowledgements}

We thank the NSF-funded LTER Network Office for support of a working group where this analysis was envisioned, the NSFfunded Drought-Net Research Coordination Network (Ecosystems Program) and the Extreme Drought in Grasslands (EDGE) project (Macrosystems Biology) for support of the analysis, Nolan Doesken and Becky Bollinger from Department of Atmospheric Sciences, Colorado State University for analytical advice and their climatological expertise, and Dr. Erem Kazancioğlu for assistance with data analysis.

\section{References}

Aviad Y, Kutiel H, Lavee H (2009) Variation of Dry Days Since Last Rain (DDSLR) as a measure of dryness along a Mediterranean - Arid transect. Journal of Arid Environments, 73, 658-665.

Avolio ML, Smith MD (2013) Mechanisms of selection: phenotypic differences among genotypes explain patterns of selection in a dominant species. Ecology, 94, 953-965.

Bailey RG (1983) Delineation of ecosystem regions. Environmental Management, 7, 365373.

Bailey RG (1989) Explanatory supplement to ecoregions map of the continents. Environmental Conservation, 16, 307-309.

Bolinger RA, Kummerow CD, Doesken NJ (2014) Attribution and characteristics of wet and dry seasons in the Upper Colorado River Basin. Journal of Climate, 27, 8661-8673.

Cherwin K, Knapp A (2012) Unexpected patterns of sensitivity to drought in three semi-arid grasslands. Oecologia, 169, 845-852.

Coe KK, Sparks JP (2014) Physiology-based prognostic modeling of the influence of changes in precipitation on a keystone dryland plant species. Oecologia, 176, 933 942.

Davidowitz G (2002) Does precipitation variability increase from mesic to xeric biomes? Global Ecology and Biogeography, 11, 143-154.

Dettinger MD, Ralph FM, Das T, Neiman PJ, Cayan DR (2011) Atmospheric rivers, floods and the water resources of California. Water, 3, 445-478.

Durack PJ, Wijffels SE, Matear RJ (2012) Ocean salinities reveal strong global water cycle intensification during 1950 to 2000. Science, 336, 455-458.

Easterling DR, Meehl GA, Parmesan C, Changnon SA, Karl TR, Mearns LO (2000a) Climate extremes: observations, modeling, and impacts. Science, 289, 2068-2074.

Easterling DR, Evans JL, Groisman PY, Karl TR, Kunkel KE, Ambenje P (2000b) Observed variability and trends in extreme climate events: a brief review. Bulletin of the American Meteorological Society, 81, 417-425.

Fischer EM, Beyerle U, Knutti R (2013) Robust spatially aggregated projections of climate extremes. Nature Climate Change, 3, 1033-1038.
Fraser LH, Henry HA, Carlyle CN et al. (2013) Coordinated distributed experiments: an emerging tool for testing global hypotheses in ecology and environmental science. Frontiers in Ecology and the Environment, 11, 147-155.

Frich P, Alexander LV, Della-Marta P, Gleason B, Haylock M, Klein Tank AMG, Peterson $\mathrm{T}$ (2002) Observed coherent changes in climatic extremes during the second half of the twentieth century. Climate Research, 19, 193-212.

Gerten D, Luo Y, Le Maire G et al. (2008) Modelled effects of precipitation on ecosystem carbon and water dynamics in different climatic zones. Global Change Biology, 14, 1-15.

Goldstein LJ, Suding KN (2014) Intra-annual rainfall regime shifts competitive interactions between coastal sage scrub and invasive grasses. Ecology, 95, 425-435.

Golluscio RA, Sala OE, Lauenroth WK (1998) Differential use of large summer rainfall events by shrubs and grasses: a manipulative experiment in the Patagonian steppe. Oecologia, 115, 17-25.

Greve P, Orlowsky B, Mueller B, Sheffield J, Reichstein M, Seneviratne SI (2014) Global assessment of trends in wetting and drying over land. Nature Geoscience, 7, 716-721.

Grime JP, Browth VK, Thompson Ket al. (2000) The response of two contrasting limestone grasslands to simulated climate change. Science, 289, 762-765.

Groisman PY, Karl TR, Easterling DR et al. (1999) Changes in the probability of heavy precipitation: important indicators of climatic change. Climatic Change, 42, 243283.

Groisman PY, Knight RW, Easterling DR, Karl TR, Hegerl GC, Razuvaev VN (2005) Trends in intense precipitation in the climate record. Journal of Climate, 18, 13261350 .

Heisler-White JL, Blair JM, Kelly EF, Harmoney K, Knapp AK (2009) Contingent productivity responses to more extreme rainfall regimes across a grassland biome. Global Change Biology, 15, 2894-2904.

Hovenden MJ, Newton PCD, Wills KE (2014) Seasonal not annual rainfall determines grassland biomass response to carbon dioxide. Nature, 511, 583-586.

Huntington TG (2006) Evidence for intensification of the global water cycle: review and synthesis. Journal of Hydrology, 319, 83-95.

IPCC (2012) Summary for policymakers. In: Managing the Risks of Extreme Events and Disasters to Advance Climate Change Adaptation. A Special Report of Working Groups I and II of the Intergovernmental Panel on Climate Change (eds Field CB, Barros V, Stocker TF, Qin D, Dokken DJ, Ebi KL, Mastrandrea MD, Mach KJ, Plattner G-K, Allen SK, Tignor M, Midgley PM), pp. 1-19. Cambridge University Press, Cambridge, UK and New York, NY, USA.

IPCC (2013) Climate Change 2013: The Physical Science Basis. Contribution of Working Group 1 to the Fifth Assessment Report of the Intergovernmental Panel on Climate Change (eds Stocker TF, Qing D, Plattner G-K, Tingor M, Allen SK, Boschung J, Nauels A, Xia Y, Bex V, Midgley PM), Cambridge University Press, Cambridge, UK, and New York, NY, USA.

Janssen E, Wuebbles DJ, Kunkel KE, Olsen SC, Goodman A (2014) Observationaland model-based trends and projections of extreme precipitation over the contiguous United States. Earth's Future, 2, 99-113.

Jentsch A (2006) Extreme climatic events in ecological research. Frontiers in Ecology and the Environment, 4, 235-236.

Jentsch A, Kreyling J, Beierkuhnlein C (2007) A new generation of climate- change experiments: events, not trends. Frontiers in Ecology and the Environment, 5, 365-374.

Karl TR, Knight RW (1998) Secular trends of precipitation amount, frequency, and intensity in the United States. Bulletin of the American Meteorological Society, 79, 231-241.

Karl TR, Trenberth KE (2003) Modern global climate change. Science, 302, 1719-1723.

Klein T, Cohen S, Yakir D (2011) Hydraulic adjustments underlying drought resistance of Pinus halepensis. Tree Physiology, 31, 637-648.

Knapp AK, Smith MD (2001) Variation among biomes in temporal dynamics of aboveground primary production. Science, 291, 481-484.

Knapp AK, Briggs JM, Koelliker JK (2001) Frequency and extent of water limitation to primary production in a mesic temperate grassland. Ecosystems, 4, 19-28.

Knapp AK, Fay PA, Blair JM et al. (2002) Rainfall variability, carbon cycling, and plant species diversity in a mesic grassland. Science, 298, 2202-2205.

Knapp AK, Beier C, Briske DD et al. (2008) Consequences of more extreme precipitation regimes for terrestrial ecosystems. BioScience, 58, 811-821.

Knapp AK, Smith MD, Hobbie SE et al. (2012) Past, present and future roles of longterm experiments in the LTER Network. BioScience, 62, 377-389.

Knapp AK, Carroll CJW, Denton EM, La Pierre KJ, Collins SL, Smith MD (2015) Differential sensitivity to regional-scale drought in six central U.S. grasslands. Oecologia. doi:10.1007/s00442-015-3233-6.

Kulmatiski A, Beard KH (2013) Woody plant encroachment facilitated by increased precipitation intensity. Nature Climate Change, 3, 833-837. 
Leuzinger S, Körner C (2010) Rainfall distribution is the main driver of runoff under future $\mathrm{CO} 2$-concentration in a temperate deciduous forest. Global Change Biology, 16, 246-254.

Loik ME, Breshears DD, Lauenroth WK, Belnap J (2004) A multi-scale perspective of water pulses in dryland ecosystems: climatology and ecohydrology of the western USA. Oecologia, 141, 269-281.

Luo YQ, Gerten D, le Maire G (2008) Modelled effects of multiple global change factors on ecosystem carbon and water dynamics in different climatic zones. Part II: interactive effects of precipitation, temperature, and $\mathrm{CO}_{2}$. Global Change Biology, 14, 1986-1999.

Luo Y, Melillo J, Niu S et al. (2011) Coordinated approaches to quantify long-term ecosystem dynamics in response to global change. Global Change Biology, 17, 843-854.

Marvel K, Bonfils C (2013) Identifying external influences on global precipitation. Proceedings of the National Academy of Sciences, 110, 19301-19306.

McKee TB, Doesken NJ, Kleist J (1993) The relationship of drought frequency and duration to time scales. Eighth Conference on Applied Climatology, American Meteorological Society, Jan 17-23, Anaheim CA, pp. 179-186.

Min SK, Zhang X, Zwiers FW, Hegerl GC (2011) Human contribution to more intense precipitation extremes. Nature, 470, 378-381.

Moran MS, Ponce-Campos GE, Huete A et al. (2014) Functional response of U.S. grasslands to the early 21st-century drought. Ecology, 95, 2121-2133.

Noy-Meir I (1973) Desert ecosystems: environment and producers. Annual Review of Ecology and Systematics, 4, 25-52.

Peng S, Piao S, Shen Z et al. (2013) Precipitation amount, seasonality and frequency regulate carbon cycling of a semi-arid grassland ecosystem in Inner Mongolia, China: a modeling analysis. Agricultural and Forest Meteorology, 178-179, 46-55.

Ponce-Campos GE, Moran MS, Huete A et al. (2013) Ecosystem resilience despite large-scale altered hydroclimatic conditions. Nature, 294, 349-352.

Porporato A, Daly E, Rodriguez-Iturbe I (2004) Soil water balance and ecosystem response to climate change. American Naturalist, 164, 625-632.

Pratt JD, Mooney KA (2013) Variation in Artemisia californica functional traits and plasticity along a steep environmental cline: implications for plant response to predicted climate change. Global Change Biology, 19, 2454-2466.

Raz-Yaseef N, Yakir D, Rotenberg E, Schiller G, Cohen S (2010) Ecohydrology of a semi-arid forest: partitioning among water balance components and its implications for predicted precipitation changes. Ecohydrology, 3, 143-154.

Raz-Yaseef N, Yakir D, Schiller G, Cohen S (2012) Dynamics of evapotranspiration partitioning in a semi-arid forest as affected by temporal rainfall patterns. Agricultural and Forest Meteorology, 157, 77-85.

Sala OE, Lauenroth WK, Parton WJ (1992) Long term soil water dynamics of the shortgrass steppe. Ecology, 73, 1175-1181.

Singh D, Tsiang M, Rajaratnam B, Diffenbaugh NS (2013) Precipitation extremes over the continental United States in a transient, high-resolution, ensemble climate model experiment. Journal of Geophysical Research: Atmospheres, 118, 7063-7086.

Smith MD (2011a) The ecological role of climate extremes: current understanding and future prospects. Journal of Ecology, 99, 651-655.

Smith MD (2011b) An ecological perspective on extreme climatic events: a synthetic definition and framework to guide future research. Journal of Ecology, 99, 656-663.

Smith MD, Knapp AK, Collins SL (2009) A framework for assessing ecosystem dynamics in response to chronic resource alterations induced by global change. Ecology, 90, 3279-3289.

Thomey ML, Collins SL, Vargas R, Johnson JE, Brown RF, Natvig DO, Friggens MT (2011) Effect of precipitation variability on net primary production and soil respiration in a Chihuahuan Desert grassland. Global Change Biology, 17, 1505-1515.
Travers SK, Eldridge DJ (2013) Increased rainfall frequency triggers an increase in litterfall rates of reproductive structures in an arid eucalypt woodland. Austral Ecology, 38, 820-830.

Trenberth KE, Dai A, Rasmussen RM, Parsons DB (2003) The changing character of precipitation. Bulletin of the American Meteorological Society, 84, 1205-1217.

Vittoz P, Randin C, Dutoit A, Bonnet F, Hegg O (2009) Low impact of climate change on subalpine grasslands in the Swiss Northern Alps. Global Change Biology, 15, 209-220.

Weltzin JF, Loik ME, Schwinning S et al. (2003) Assessing the response of terrestrial ecosystems to potential changes in precipitation. BioScience, 53, 941-952.

Wilcox KR, Von FJ, Muscha J, Petersen M, Knapp AK (2015) Contrasting above- and belowground sensitivity of three Great Plains grasslands to altered rainfall regimes. Global Change Biology, 21, 335-344.

Wu C, Chen JM, Desai AR, Lafleur PM, Verma SB (2013) Positive impacts of precipitation intensity on monthly $\mathrm{CO}_{2}$ fluxes in North America. Global and Planetary Change, 100, 204-214.

Yu K, D'Odorico P (2014) Climate, vegetation, and soil controls on hydraulic redistribution in shallow tree roots. Advances in Water Resources, 66, 70-80.

Zeglin LH, Bottomley PJ, Jumpponen A et al. (2013) Altered precipitation regime affects the function and composition of soil microbial communities on multiple time scales. Ecology, 94, 2334-2345.

Zeppel MJB, Wilks JV, Lewis JD (2014) Impacts of extreme precipitation and seasonal changes in precipitation on plants. Biogeosciences, 11, 3083-3093.

Zhang B, Cao J, Bai Y, Zhou X, Ning Z, Yang S, Hu L (2013) Effects of rainfall amount and frequency on vegetation growth in a Tibetan alpine meadow. Climatic Change, 118, 197-212.

\section{Supporting Information}

Additional Supporting Information may be found in the online version of this article:

Table S1. Model results from permutational multivariate analysis of variance testing for differences among extreme wet, dry, and average years in each of 12 ecoregions

Figure S1. Percentage contribution of five precipitation regime attributes to divergence between extreme wet and average years, and extreme dry and average years, for 12 different terrestrial ecoregions.

Table S2. Results from one-way mixed model ANOvA for each precipitation attribute for the each of the 12 ecoregion divisions

Table S3. Temporal trends in the occurrence of extreme wet and dry years by decade for the 12 ecoregions

Figure S2. Temporal trends in the occurrence of extreme wet and dry years by decade for all 144 sites. 